\title{
A EDUCAÇÃO DE JOVENS E ADULTOS (EJA) NO LITORAL SUL DA BAHIA: REALIDADE E DESAFIOS NO ANO CONTINUUM 2020/2021
}

\author{
Janille da Costa Pinto ${ }^{1}$ \\ Cátia Regina Conceição dos Santos ${ }^{2}$ \\ Arlete Ramos dos Santos ${ }^{3}$
}

\section{RESUMO}

Este artigo apresenta reflexões sobre a Educação de Jovens e Adultos (EJA) ofertada na Rede Estadual de Educação da Bahia, com o recorte para as escolas situadas no Território de Identidades Litoral Sul (NTE 05). Tem como foco principal apresentar um panorama dessa modalidade dentro do ano continuum 2020/2021 no que tange à sua oferta, formas de organização e fluxo escolar, além de investigar quais recursos tecnológicos e estratégias pedagógicas estão sendo executadas no Ensino Remoto. A metodologia está baseada na pesquisa qualitativa - descritiva, em que utiliza a análise bibliográfica e documental como coleta de dados, que foram interpretados "à luz" da técnica de análise de conteúdo de Minayo (2000) e de referências de teóricos como Freire (1996) e Arruda (2020). Os resultados têm mostrado que a EJA precisa intensificar esforços para a realização da busca ativa e proposições de estratégias pedagógicas mediadas por

\footnotetext{
${ }^{1}$ Mestre em Ciências da Educação. Coordenadora Pedagógica SEC-BA . Professora da Rede Municipal de Educação de Ilhéus/BA - Núcleo Territorial de Educação Litoral Sul da Bahia (NTE 05). Integra o Grupo de Estudos e Pesquisas Movimentos Sociais, Diversidade e Educação do Campo e da Cidade (GEPEMDECC-UESB-UESC), com registro no CNPQ. ORCID: https://orcid.org/0000-0001-6564-1878. E-mail: janillecp@gmail.com.

${ }^{2}$ Mestre em Educação. Professora da Rede Municipal de Educação de Ilhéus/BA. Integra o Grupo de Estudos Movimentos Sociais, Diversidade Cultural e Educação do Campo e da Cidade (GEPEMDECC-UESB-UESC) com registro no CNPQ. ORCID: https://orcid.org/0000-0002-4646-3305 . E-mail: catia_pm@hotmail.com.

3 Doutora em Educação. Pós-doutora em Educação pela UNESP. Professora Adjunta da Universidade Estadual de Santa Cruz (UESC-BA). Integra o Grupo de Estudos Movimentos Sociais, Diversidade Cultural e Educação do Campo e da Cidade (GEPEMDECC-UESBUESC), com registro no CNPQ. ORCID: https://orcid.org/0000-0003-0217-3805. E-mail arlerp@hotmail.com
} 
tecnologias digitais e/ou analógicas que possibilitem manter o vínculo com seus/suas alunos (as) e proporcionem a aprendizagem significativa para a construção de sua cidadania.

Palavras-chave: EJA. Ensino Remoto. Recursos.

\section{YOUTH AND ADULT EDUCATION (EJA) IN THE SOUTH COAST OF BAHIA: REALITY AND CHALLENGES IN THE YEAR 2020/2021 CONTINUUM}

\section{ABSTRACT}

This article presents reflections on Youth and Adult Education (EJA) offered in the State Education Network of Bahia, with a focus on schools located in the Territory of Identities Litoral Sul (NTE-05). Its main focus is to present an overview of this modality within the year $2020 / 2021$ with regard to its offer, forms of organization and school flow, in addition to investigating which technological resources and pedagogical strategies are being implemented in Remote Education. The methodology is based on qualitative - descriptive research, using bibliographic and documentary analysis as data collection, which were interpreted "in the light" of Minayo's (2000) content analysis technique and theoretical references such as Freire (1996) and ARRUDA (2020). The results have shown that EJA needs to intensify efforts to carry out the active search and propositions of pedagogical strategies mediated by digital and / or analog technologies that make it possible to maintain the bond with its students and provide meaningful learning for the child. building their citizenship.

Keywords: EJA. Remote Teaching. Resources. 


\section{EDUCACIÓN DE JÓVENES Y ADULTOS (EJA) EN LA COSTA SUR DE BAHIA: REALIDAD Y DESAFíOS EN EL CONTINUO AÑO 2020/2021}

\section{RESUMEN}

Este artículo presenta reflexiones sobre la Educación de Jóvenes y Adultos (EJA) que se ofrece en la Red de Educación del Estado de Bahía, con un enfoque en las escuelas ubicadas en el Territorio de Identidad Litoral Sul (NTE-05). Su principal enfoque es presentar un panorama de esta modalidad dentro del año continuo 2020/2021 en cuanto a su oferta, formas de organización y flujo escolar, además de indagar qué recursos tecnológicos y estrategias pedagógicas se están implementando en Educación Remota. La metodología se basa en una investigación cualitativo-descriptiva, que utiliza el análisis bibliográfico y documental como recolección de datos, los cuales fueron interpretados "a la luz" de la técnica de análisis de contenido de Minayo (2000) y referencias teóricas como Freire (1996) y ARRUDA (2020). Los resultados han demostrado que EJA necesita intensificar los esfuerzos para llevar a cabo la búsqueda activa y propuestas de estrategias pedagógicas mediadas por tecnologías digitales y / o analógicas que permitan mantener el vínculo con sus estudiantes y brindar aprendizajes significativos para la construcción de su ciudadanía.

Palabras clave: EJA. Enseñanza remota. Recursos.

\section{INTRODUÇÃO}

Ao falarmos sobre a Educação de Jovens e Adultos (EJA), devemos recordar que ela é classificada como uma modalidade da educação brasileira que busca garantir o direito à educação para pessoas que, em sua maioria, não tiveram acesso à educação formal; carregam um histórico significativo de repetência; necessitaram abandonar os estudos por diversos motivos; e/ou que carregam em suas bagagens emocionais o estigma de baixa autoestima e de perfil socioeconômico deficitário. Logo, precisam de um modelo 
pedagógico e curricular que dê conta dessas especificidades para que consigam percorrer sua caminhada escolar no ensino formal.

Nesse contexto, compreende-se que o ensino e a aprendizagem na EJA devam ser realizados de forma que aproximem as áreas do conhecimento e favoreçam a inter ou transdisciplinaridade de sua proposta curricular. Desse modo, entendemos que a proposta pedagógica da EJA precisa estar pautada nas concepções teóricas e epistemológicas da Educação Popular, defendida por Paulo Freire, que percebe a vinculação entre os processos educativos, as lutas e os anseios da classe trabalhadora, na contribuição para sua compreensão e inclusão no mundo social.

Mediante essa realidade do público da EJA, optamos em traçar um panorama dessa modalidade nas escolas da Rede Estadual de Educação da Bahia, especificamente no Território de Identidades Litoral Sul (NTE 05), no contexto atual do ano letivo denominado continuum 2020/2021, que foi organizado para atender às demandas da pandemia da covid-19. Assim, analisamos o fluxo escolar e as formas de organização curricular dessa modalidade durante esse recorte temporal, além de investigar como é ofertada essa educação, quais recursos tecnológicos e estratégias pedagógicas são planejadas e efetivadas no formato de Ensino Remoto Emergencial, que foi regulamentado pela Secretaria e Conselho Estadual de Educação da Bahia.

Por meio desses objetivos, busca-se responder: Como se concretiza o Ensino Remoto nas escolas que ofertam a EJA no âmbito do Território de Identidades Litoral Sul (NTE 05)? Para responder a esse questionamento, foi realizada uma pesquisa qualitativa e descritiva, visto que, segundo os estudos de Oliveira (2016, p. 59),

facilita descrever a complexidade do problema estudado, bem como analisar a interação entre variáveis, compreender e classificar determinados processos sociais, oferecer contribuições no processo de mudanças [...].

Recorremos à pesquisa bibliográfica com a finalidade de entrar em contato direto com obras, produções científicas e documentos que trazem informações sobre o tema do trabalho 
(OLIVEIRA, 2016), e documental, que "recorre a fontes mais diversificadas e dispersas, sem tratamento analítico" (FONSECA, 2002, p. 32), nas quais foram disponibilizadas pelo NTE e plataformas da SEC-BA, dentre outros documentos como, leis, resoluções e decretos existentes sobre a EJA. Cabe destacar que na fase da pesquisa na qual analisamos o documento Plano 21, em que consta quais os recursos e estratégias pedagógicas estão sendo planejadas e realizadas no ano continuum 2020/2021 pelas escolas, disponibilizado na Plataforma SAGA, realizamos o procedimento de amostragem (devido à grande quantidade de informações por escolas), isto é, "aplicamos a uma parcela convenientemente selecionada do universo (população); é um subconjunto do universo" (MARCONI; LAKATOS, 2003, p. 163). Assim, analisamos dados de uma escola por município, escolhida aleatoriamente.

Esses dados foram analisados e interpretados seguindo a técnica de análise de conteúdo de Minayo (2000) e baseados na perspectiva da metodologia dialética, visto que "[...] a dialética é o pensamento crítico que se propõe a compreender a 'coisa em si' e sistematicamente se pergunta como é possível chegar à compreensão da realidade" (KOSIK, 2002, p. 20). Segundo Minayo (2000), uma pesquisa dialética, ao ter por objetivo a crítica, somente é possível com aprofundamento do conhecimento da realidade e com sustentação teórica. O que nos leva a dar importância constante à conexão entre teoria e prática.

Portanto, pretende-se expor um panorama crítico sobre a realidade e desafios enfrentados pela EJA no Território de Identidades Litoral Sul (NTE 05) no que tange à efetivação do Ensino Remoto, pois se faz necessário conhecer como a modalidade está sendo planejada e executada para conter os índices de evasão e repetência, justamente porque os (as) estudantes ficaram o ano calendário de 2020 afastados das escolas devido à suspensão das aulas decorrentes da pandemia da covid-19 e agora em 2021 a educação precisa agregar esforços para a realização de busca ativa desses (as) estudantes. 


\section{O ENSINO REMOTO DA EJA NO LITORAL SUL DA BAHIA}

O Território de Identidade Litoral Sul (NTE 05) está localizado no Sul baiano, área em $\mathrm{km}^{2}$ de 14.665 , com a densidade demográfica de 53,9 hab $/ \mathrm{km}^{2}$, composto por 26 municípios constituídos a partir das especificidades de cada região. Entende-se como território:

Um espaço físico, geograficamente definido, geralmente contínuo, caracterizado por critérios multidimensionais, tais como o ambiente, a economia, a sociedade, a cultura, a política e as instituições, e uma população com grupos sociais relativamente distintos, que se relacionam interna e externamente por meio de processos específicos, onde se pode distinguir um ou mais elementos que indicam identidade, coesão social, cultural e territorial (BAHIA, 2021h, on-line).

Assim, fazem parte desse território: Almadina, Arataca, Aurelino Leal, Barro Preto, Buerarema, Camacan, Canavieiras, Coaraci, Floresta Azul, Ibicaraí, Ilhéus, Itabuna, Itacaré, Itaju do Colônia, Itajuípe, Itapé, Itapitanga, Jussari, Maraú, Mascote, Pau-Brasil, Santa Luzia, São José da Vitória, Ubaitaba, Una e Uruçuca (BAHIA, 2019).

Nesse território, a Rede Estadual, durante esse ano continuum 2020/2021, possui 69 unidades escolares (59 na sede e 10 distritos), contendo 23 anexos, com total de 38.789 alunos (as) matriculados (as) e conta com 3.003 profissionais da educação (NúCLEO TERRITORIAL DE EDUCAÇÃO LITORAL SUL, 2021). Ressalta-se que devido à pandemia da covid-19 as aulas no ano letivo de 2020, que iniciaram em fevereiro, foram suspensas em março em todo o território da Bahia, por meio do Decreto n. ${ }^{0} 19.586$ (BAHIA, 2020). Mas, as matrículas já tinham se concretizado. Dessa forma, em 2020 a Rede Estadual no Litoral Sul tinha matriculado 5.469 estudantes nas turmas de EJA (anos iniciais, finais e médio).

Percebemos que o índice de matrícula nesse ano foi menor do que a matrícula inicial do ano anterior, visto que em 2019 nesse território tinham 6.666 alunos (as) matriculados (as) na EJA (anos iniciais, finais e médio). Entretanto, no final do ano de 2019 foram aprovados menos da metade (3.080 alunos [as]). Apesar de ter 
matrícula inicial maior do que 2020, a taxa de abandono e reprovação foi grande, como podemos verificar na Figura 1 a seguir:

Figura 1 - Fluxo da EJA no Território de Identidade Litoral Sul, 2019

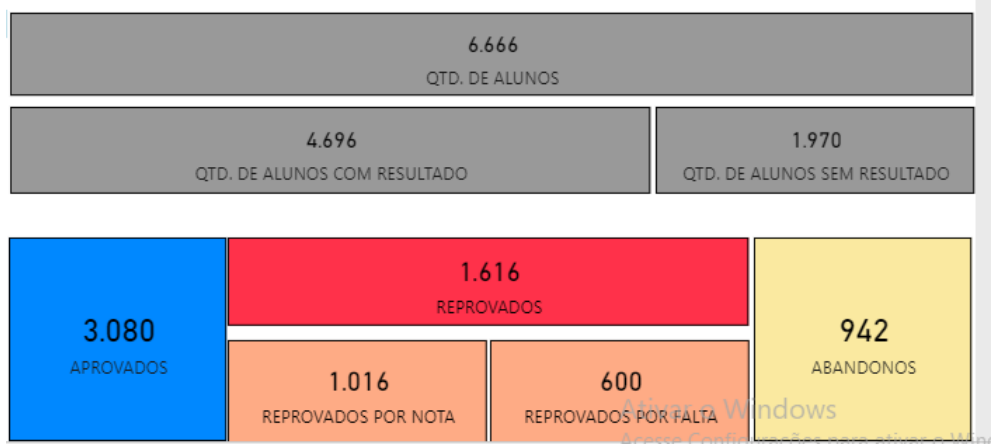

Fonte: Portal BI, Sistema de relatórios da Bahia, 2021a.

Diante disso, percebemos que nesse período analisado somente $40,48 \%$ de alunos (as) conseguiram chegar até o final do ano letivo com êxito. Já 25,89\% ficaram sem resultados, 21,24\% foram reprovados e $12,38 \%$ abandonaram os estudos. Mediante esse panorama, percebemos que a taxa de reprovação e abandono foi muito alta. Por essa razão, devemos pensar sobre o que alerta Haddad e Di Pierro (2000): "a ampliação da oferta escolar não foi acompanhada de uma melhoria das condições do ensino, de modo que, hoje, temos mais escolas, mas sua qualidade é muito ruim" (HADDAD; DI PIERRO, 2000, p. 125).

Como já pontuado anteriormente, o ano letivo de 2020 foi suspenso. Por conseguinte, não temos o fluxo escolar desse período. Ao iniciar o ano calendário de 2021, as aulas retornaram em 15 de março no formato remoto. Assim, o ano letivo iniciou com outra roupagem para dar conta das horas correspondentes aos anos 2020 e 2021. Então, foi denominado de ano continuum 2020/2021, organizado e executado no modelo de Ensino Remoto, isto é,

uma modalidade de ensino ou aula que pressupõe o distanciamento geográfico de professores e estudantes e vem sendo adotada nos diferentes níveis de ensino [...] em função das restrições 
impostas pelo covid-19. (MOREIRA; SCHLEMMER, 2020, p. 8)

Dessa maneira, as matrículas realizadas em 2020 foram renovadas automaticamente para 2021, garantindo o turno que o (a) estudante se matriculou, conforme autoriza o artigo $2^{\circ}$ da Portaria $n .^{\circ}$ 711, de 10 de março de 2021.

Portanto, no início do ano continuum 2020/2021, a realização das matrículas em todas as etapas e modalidades de ensino da Rede Estadual aconteceu no Litoral Sul durante o período de 22 a 25/03/2021, estando amparada pela portaria n. ${ }^{\circ} 711 / 2021$, na qual também abriu matrícula para estudantes oriundos das Redes Municipais de Ensino e Escolas Privadas, que foram realizadas

preferencialmente, via Internet, através do endereço eletrônico www.sacdigital.ba.gov.br, do aplicativo SAC DIGITAL (disponível gratuitamente nos sistemas ANDROID e IOS) ou, ainda, em qualquer Unidade Escolar Estadual. (BAHIA, ARTIGO 6, 2021b).

Destaca-se que durante todo ano de 2021 as unidades escolares estaduais estarão com matrículas abertas para alunos (as) provenientes de outras redes, pois a finalização dos calendários escolares de alguns munícipios, as horas relativas ao ano de 2020, está sendo concluída no decorrer do ano calendário de 2021.

Mediante esse contexto, as escolas que ofertam a EJA na Rede Estadual seguiram a mesma organização e quantidade limite de matrícula por cada etapa e tipo de ensino a saber:

1. Tempos Formativos I e II (até 35 alunos [as]) e Tempos Formativos III (até 40 alunos [as]). As suas matrículas ocorrem de forma anual; as aulas são presenciais e exigem frequência diária; possuem os currículos organizados em eixos temáticos, temas geradores e áreas de conhecimento. O centro do processo de formação são as experiências de vida e estratégias de sobrevivência dos sujeitos jovens, adultos (as) e idosos (as). O curso total é composto de 3 segmentos distribuídos ao longo de 7 anos: $01^{\circ}$ 
Tempo Formativo (equivale ao $1^{\circ}$ segmento da educação fundamental); o $2^{\circ}$ Tempo Formativo (equivale ao $2^{\circ}$ segmento da educação fundamental); e o $3^{\circ}$ Tempo Formativo (equivale ao ensino médio) (BAHIA, 2021c, on-line).

2. Tempo de Aprender I, (até 35 alunos [as]) e Tempo de Aprender II (até 40 alunos [as]). A matrícula e a estrutura didática são semestrais, com aulas semipresenciais, em que os (as) alunos (as) podem frequentar a escola 3 vezes por semana e têm garantido o direito de aproveitamento de estudos já realizados nos diferentes componentes curriculares. $\mathrm{O}$ curso total é composto de 2 segmentos distribuídos ao longo de 4 anos: Tempo de Aprender I (equivale ao $2^{\circ}$ segmento da educação fundamental) e Tempo de Aprender II (equivale ao ensino médio) (BAHIA, 2021C, on-line).

3. Tempo Juvenil I e II (até 35 alunos [as]), se constitui em uma Proposta Educacional para Atendimento a Adolescentes de 15 a 17 anos que não concluíram o Ensino Fundamental (BAHIA, 2021c, on-line). Esse formato surge de uma demanda que emergiu e se ampara no Parecer CNE/CEB n. ${ }^{\circ} 6$ (BRASIL, 2010b), da Resolução CNE/CEB n. ${ }^{\circ} 3$ (BRASIL, 2010a), que regulamenta as Diretrizes Operacionais para a Educação de Jovens e Adultos, sendo organizada numa lógica curricular que "supera o modelo seriado, superando também a visão que limita os educandos e os educadores a um conjunto de conteúdos e habilidades já predeterminados a serem atingidos no período de um ano" (BAHIA, 2013, p. 20).

Dessa forma, para o ano continuum 2020/2021 a EJA é ofertada em 21 municípios do Litoral Sul, em 43 escolas estaduais e com o total de 6.334 alunos (as) regularmente matriculados até o dia 16 de abril de 2021 (NÚCLEO TERRITORIAL DE EDUCAÇÃO LITORAL SUL, 2021). Para melhor compreensão dessa distribuição segue 0 
Quadro 1, em que apresentamos os nomes das unidades escolares e quantidade de matrícula em cada etapa e eixo da EJA. Vale frisar que no território do Litoral Sul não há nenhuma matrícula na EJA no tipo Saberes do Campo.

Quadro 1 - Unidades Escolares que ofertam EJA 2020/2021

\begin{tabular}{|c|c|c|c|c|c|c|c|c|c|}
\hline & Municípios & Unidades Escolares & & & al de & natrí & & & \\
\hline & & & 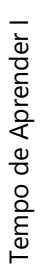 & 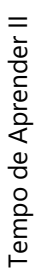 & 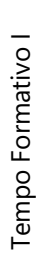 & 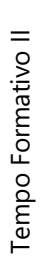 & 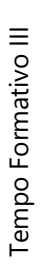 & 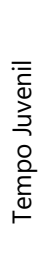 & 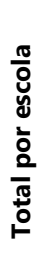 \\
\hline 1 & Almadina & $\begin{array}{l}\text { Colégio Estadual Senador } \\
\text { Luiz Viana Filho }\end{array}$ & 0 & 0 & 0 & 0 & 66 & 0 & 66 \\
\hline 2 & Arataca & $\begin{array}{l}\text { Colégio Estadual Bráulio } \\
\text { Xavier }\end{array}$ & 0 & 0 & 0 & 0 & 70 & 0 & 70 \\
\hline 3 & $\begin{array}{l}\text { Aurelino } \\
\text { Leal }\end{array}$ & $\begin{array}{l}\text { Colégio Estadual } \\
\text { Professora Maria Olímpia }\end{array}$ & 0 & 0 & 0 & 0 & 163 & 0 & 163 \\
\hline 4 & Barro Preto & $\begin{array}{l}\text { Colégio Estadual } \\
\text { Lomanto Junior }\end{array}$ & 0 & 0 & 0 & 0 & 77 & 0 & 77 \\
\hline 5 & Buerarema & $\begin{array}{l}\text { Colégio Estadual Enedina } \\
\text { Oliva }\end{array}$ & 0 & 0 & 0 & 0 & 153 & 0 & 153 \\
\hline \multirow{2}{*}{6} & \multirow{2}{*}{ Camacan } & $\begin{array}{l}\text { Colégio Estadual } \\
\text { Polivalente de Camacan }\end{array}$ & 0 & 0 & 0 & 0 & 177 & 0 & 177 \\
\hline & & $\begin{array}{l}\text { Colégio Estadual Anísio } \\
\text { Loureiro }\end{array}$ & 0 & 0 & 0 & 0 & 42 & 0 & 42 \\
\hline 7 & Canavieiras & $\begin{array}{l}\text { Colégio Modelo Luís } \\
\text { Eduardo Magalhães }\end{array}$ & 0 & 0 & 0 & 0 & 258 & 0 & 258 \\
\hline 8 & Coaraci & $\begin{array}{l}\text { Colégio Estadual } \\
\text { Almakazir Gally Galvão }\end{array}$ & 0 & 0 & 0 & 0 & 132 & 0 & 132 \\
\hline 9 & Ibicaraí & $\begin{array}{l}\text { Colégio Estadual Luís } \\
\text { Eduardo Magalhães }\end{array}$ & 0 & 0 & 0 & 0 & 277 & 0 & 277 \\
\hline \multirow{4}{*}{10} & \multirow{4}{*}{ Ilhéus } & $\begin{array}{l}\text { Colégio Estadual } \\
\text { Professor Fabio Araripe } \\
\text { Goulart }\end{array}$ & 0 & 0 & 0 & 0 & 173 & 0 & 173 \\
\hline & & $\begin{array}{l}\text { Escola Estadual Indígena } \\
\text { Tupinambá de Abaeté }\end{array}$ & 0 & 0 & 18 & 9 & 15 & 0 & 42 \\
\hline & & $\begin{array}{l}\text { Colégio Estadual do } \\
\text { Iguape e seus anexos }\end{array}$ & 0 & 0 & 0 & 10 & $\begin{array}{l}79 \\
30\end{array}$ & 26 & 145 \\
\hline & & $\begin{array}{l}\text { Colégio Estadual Estado } \\
\text { do Ceará }\end{array}$ & 0 & 0 & 0 & 37 & 88 & 0 & 125 \\
\hline
\end{tabular}




\begin{tabular}{|c|c|c|c|c|c|c|c|c|c|}
\hline & & $\begin{array}{l}\text { Colégio Estadual Eduardo } \\
\text { Catalão }\end{array}$ & 0 & 0 & 0 & 0 & 83 & 0 & 83 \\
\hline & & $\begin{array}{l}\text { Colégio da Polícia Militar } \\
\text { - COM Romulo Galvão }\end{array}$ & 53 & 75 & 0 & 0 & 0 & 0 & 128 \\
\hline & & $\begin{array}{l}\text { Colégio Estadual Paulo } \\
\text { Américo de Oliveira }\end{array}$ & 0 & 0 & 0 & 0 & 347 & 0 & 347 \\
\hline & & \begin{tabular}{|l|} 
Colégio Estadual Rotary \\
Renato Leite da Silveira \\
\end{tabular} & 0 & 0 & 0 & 0 & 0 & 77 & 77 \\
\hline & & $\begin{array}{l}\text { Colégio Estadual } \\
\text { Indígena Tupinambá de } \\
\text { Olivença }\end{array}$ & 0 & 0 & 67 & 52 & 50 & 0 & 169 \\
\hline & & $\begin{array}{l}\text { Colégio Estadual Jorge } \\
\text { Calmon }\end{array}$ & 0 & 0 & 0 & 0 & 67 & 0 & 67 \\
\hline & & $\begin{array}{l}\text { Colégio Estadual } \\
\text { Indígena Tupinambá } \\
\text { Amotara e seus anexos }\end{array}$ & 0 & 0 & $\begin{array}{c}45 \\
\text { sede } \\
14 \\
16 \\
7\end{array}$ & $\begin{array}{c}12 \\
\text { sede } \\
11 \\
13 \\
8 \\
\end{array}$ & $\begin{array}{c}44 \\
\text { sede } \\
2 \\
8\end{array}$ & 0 & 179 \\
\hline & & $\begin{array}{l}\text { Colégio Estadual } \\
\text { Indígena Tupinambá de } \\
\text { Acuípe de Baixo e seus } \\
\text { anexos } \\
\end{array}$ & 0 & 0 & $\begin{array}{c}14 \\
\text { sede } \\
16 \\
1 \\
\end{array}$ & 16 & 23 & 0 & 70 \\
\hline & & \begin{tabular}{|l|} 
Colégio Estadual Moyses \\
Bohana \\
\end{tabular} & 0 & 0 & 0 & 0 & 106 & 0 & 106 \\
\hline & & $\begin{array}{l}\text { Colégio Estadual de } \\
\text { Itabuna e seus anexos }\end{array}$ & $\begin{array}{l}216 \\
\text { sede } \\
187\end{array}$ & $\begin{array}{l}339 \\
\text { sede } \\
70\end{array}$ & 0 & 0 & 0 & 0 & 812 \\
\hline 11 & Itabuna & \begin{tabular}{|l|} 
Colégio Estadual Inácio \\
Tosta Filho \\
\end{tabular} & 0 & 0 & 0 & 0 & 174 & 0 & 174 \\
\hline & & $\begin{array}{l}\text { Complexo Integrado de } \\
\text { Educação de Itabuna - } \\
\text { Cie de Itabuna }\end{array}$ & 0 & 0 & 0 & 0 & 64 & 0 & 64 \\
\hline & & \begin{tabular}{|l|} 
Colégio Modelo Luís \\
Eduardo Magalhaes
\end{tabular} & 0 & 0 & 0 & 0 & 139 & 0 & 139 \\
\hline & Itabuna & $\begin{array}{l}\text { Colégio Estadual General } \\
\text { Osório }\end{array}$ & 0 & 0 & 0 & 0 & 66 & 0 & 66 \\
\hline & Itabuna & $\begin{array}{l}\text { Colégio Estadual Felix } \\
\text { Mendonça }\end{array}$ & 0 & 0 & 0 & 0 & 70 & 0 & 70 \\
\hline & & \begin{tabular}{|l|} 
Centro Integrado Oscar \\
Marinho Falcão \\
\end{tabular} & 0 & 0 & 0 & 0 & 151 & 0 & 151 \\
\hline 12 & Itacaré & $\begin{array}{l}\text { Colégio Estadual Aurelino } \\
\text { Leal }\end{array}$ & 0 & 0 & 0 & 0 & 147 & 0 & 147 \\
\hline & I Itacare & \begin{tabular}{|l|} 
Colégio Estadual de \\
Taboquinhas \\
\end{tabular} & 0 & 0 & 0 & 0 & 117 & 0 & 117 \\
\hline 13 & Itaju do & \begin{tabular}{|l|} 
Colégio Estadual \\
Cordeiro de Miranda \\
\end{tabular} & 0 & 0 & 0 & 0 & 69 & 0 & 69 \\
\hline 13 & Colônia & $\begin{array}{l}\text { Colégio Estadual de } \\
\text { Palmira }\end{array}$ & 0 & 0 & 0 & 0 & 1 & 0 & 1 \\
\hline
\end{tabular}




\begin{tabular}{|c|l|l|c|c|c|c|c|c|c|}
14 & Itajuípe & $\begin{array}{l}\text { Colégio Polivalente de } \\
\text { Itajuípe }\end{array}$ & 0 & 0 & 0 & 0 & 229 & 0 & $\mathbf{2 2 9}$ \\
\hline 15 & Itapé & $\begin{array}{l}\text { Colégio Estadual Dom } \\
\text { Paulo Lopes de Faria } \\
\text { (antigo Col. Alzair } \\
\text { Martins da Silva) }\end{array}$ & 0 & 0 & 0 & 0 & 117 & 0 & $\mathbf{1 1 7}$ \\
\hline 16 & Jussari & $\begin{array}{l}\text { Colégio Estadual Amélia } \\
\text { Amado }\end{array}$ & 0 & 0 & 0 & 0 & 97 & 0 & $\mathbf{9 7}$ \\
\hline 17 & $\begin{array}{l}\text { Pau-Brasil } \\
\text { Pau-Brasil }\end{array}$ & $\begin{array}{l}\text { Colégio Estadual da } \\
\text { Aldeia Indígena } \\
\text { Caramuru Paraguaçu }\end{array}$ & 0 & 0 & 17 & 7 & 55 & 0 & $\mathbf{7 9}$ \\
\cline { 2 - 11 } & $\begin{array}{l}\text { Colégio Estadual Luís } \\
\text { Eduardo Magalhães }\end{array}$ & 0 & 0 & 0 & 0 & 128 & 0 & $\mathbf{1 2 8}$ \\
\hline 18 & $\begin{array}{l}\text { São José } \\
\text { da Vitoria }\end{array}$ & $\begin{array}{l}\text { Colégio Estadual Treze } \\
\text { de Junho }\end{array}$ & 0 & 0 & 0 & 0 & 65 & 0 & $\mathbf{6 5}$ \\
\hline 20 & Ubaitaba & $\begin{array}{l}\text { Colégio Estadual } \\
\text { Octacílio Manoel Gomes }\end{array}$ & 0 & 0 & 0 & 0 & 207 & 0 & $\mathbf{2 0 7}$ \\
\hline 21 & Una & $\begin{array}{l}\text { Colégio Estadual } \\
\text { Menandro Minahim }\end{array}$ & 0 & 0 & 0 & 0 & 293 & 0 & $\mathbf{2 9 3}$ \\
\hline & $\begin{array}{l}\text { Colégio Estadual } \\
\text { Carneiro Ribeiro }\end{array}$ & 0 & 0 & 0 & 0 & 182 & 0 & $\mathbf{1 8 2}$ \\
\hline
\end{tabular}

Fonte: Elaborado pelas autoras, baseado nos dados do Sistema de Gestão Escolar (SGE), BAHIA (2021d).

Ao analisar o Quadro 1, percebemos que o total de matrícula para o ano continuum 2020/2021 diminuiu em relação à matrícula que tinha em fevereiro de 2020. Com isso, entendemos que devido à suspensão das aulas em 2020 muitos (as) estudantes que pretendiam estudar na EJA não retornaram. Portanto, as escolas precisam realizar ações que favoreçam a busca ativa desses (as) estudantes, para assim tentar combater a evasão que se caracteriza por ser uma luta contra a marginalização dos indivíduos das classes populares, com percursos escolares interrompidos. Sobre isso, Saviani (2018) afirma que, "tratase de retomar vigorosamente a luta contra a seletividade, a discriminação e o rebaixamento do ensino das camadas populares" (SAVIANI, 2018, p. 25).

É dentro desse cenário de diminuição de matrícula que a EJA sobrevive dentro da estrutura escolar na busca de "superar a concepção compensatória, fundamentada nos princípios de recuperação de um tempo de escolaridade perdido no passado" (SANTOS; LIMA; NERY, 2019, p. 8). Destarte, para se concretizar no contexto de Ensino Remoto no ano continuum 2020/2021, foi 
elaborado para toda a Rede Estadual de Ensino da Bahia, o Plano 21, que é um Plano de Ação que envolve monitoramento e acompanhamento da educação das unidades escolares estaduais da Bahia, disponível na Plataforma SAGA, isto é, "sistema de apoio à gestão da aprendizagem e desenvolvido pela SEC para auxiliar no planejamento, acompanhamento pedagógico e avaliação" (BAHIA, 2021i, on-line).

O Plano 21 é composto por 10 etapas: Clima escolar; Perfil das famílias; Acessibilidade tecnológica; Atividades realizadas; Avaliação diagnóstica; Busca ativa; Planejamento Curricular; Atividades Curriculares Complementares (ACC); Diretrizes para as modalidades; e Validação. Em cada uma dessas etapas foram solicitadas informações para as equipes escolares, que permitem realizar 0 acompanhamento das ações e estratégias adotadas no ensino remoto.

Ao analisar o Plano 21 disponibilizado na Plataforma SAGA, das 43 escolas que ofertam a modalidade EJA, no que tange aos recursos e estratégias pedagógicas que estão sendo planejadas e realizadas nesse ano continuum 2020/2021, percebemos que a quantidade de dados para analisar não comportaria em um só artigo. Assim, concretizamos a análise e a interpretação desses dados baseadas em uma amostra composta por uma escola de cada município, totalizando 21 escolas escolhidas aleatoriamente.

Todas essas escolas estão ofertando o ensino no formato remoto, no qual realizam "[...] adaptação temporária das metodologias utilizadas no regime presencial [...]" e customizam "[...] os materiais para realização das atividades [...]" (ALVES, 2020, p. 358), mediadas pelas tecnologias digitais e analógicas.

Nesse contexto, entendemos que os (as) professores (as) e alunos (as), a depender das estratégias pedagógicas utilizadas, necessitam ter acesso à internet para disponibilizarem as atividades e materiais de estudo. Logo, buscamos conhecer o tempo de conectividade diária à internet. Verificamos que a maioria dos (as) alunos (as) acessam menos de 2 horas por dia e a maioria dos (as) professores (as) acessam mais de 2 horas por dia. Com isso, percebemos que se o (a) professor (a) da EJA utilizar na sua prática educativa estratégias pedagógicas que necessitem ser mediadas pela 
internet não irá alcançar nem a metade dos (as) alunos (as). Entretanto, conforme afirma Arruda (2020), as "tecnologias tornaramse as principais referências potencializadoras de iniciativas voltadas para a manutenção da conexão educacional" (ARRUDA, 2020, p. 263).

Buscamos, também, conhecer por quais tipos de equipamentos os (as) alunos (as) e professores (as) dispõem para acessar a internet. Notamos que a maioria deles (as) acessam por meio do celular. Essa informação comunga com os resultados encontrados por Arruda (2020), em que constatou que o celular é "o equipamento mais utilizado para acesso à Internet, chegando a mais de $97 \%$ em todas as regiões" (ARRUDA, 2020, p. 269).

Mediante esse dado, podemos entender que prática pedagógica utilizada por esses (as) professores (as), para efetivar o ensino remoto, isto é, o envio e recebimento de atividades, momento de sanar dúvidas e até realização de aulas on-line, está sendo mediada por esse aparelho. Embora o celular não favoreça de forma satisfatória o aprendizado, como bem destaca Arruda (2020, p. 272):

uma das críticas que se coloca quanto ao uso do celular para acesso à informação diz respeito ao tamanho da tela e impossibilidade de se efetuar leitura de documentos [...] à compatibilidade dos arquivos [...] (ARRUDA, 2020, p. 272).

Investigamos também como os (as) professores (as) estão executando o Planejamento Curricular. Constatamos que mais de $80 \%$ das equipes pedagógicas conhecem os Organizadores Curriculares Essenciais (OCE) sugeridos pela SEC para apoiar o planejamento pedagógico. Os OCE se constituem em:

uma estrutura de planejamento e de referência para o trabalho pedagógico, a ser desenvolvido pelos (as) professores (as) dos componentes curriculares, em todas os anos/séries das etapas do Ensino Fundamental e do Ensino Médio. Nos OCE são apresentadas as aprendizagens essenciais do currículo, de forma organizada, o que possibilitará uma visão progressiva da aprendizagem no ano e entre anos, com atenção especial às séries/anos de mudança de etapa. (BAHIA, 2021e, p. 3). 
Notamos, também, que a maioria das escolas utiliza sequências didáticas nas aulas da EJA, como podemos destacar na resposta da escola $A$ (2021):

A cada unidade elegemos temáticas que estejam relacionadas aos interesses e necessidades das turmas. O tema é apresentado às turmas juntamente com as competências e habilidades que se pretende construir. A partir destas temáticas escolhemos estratégias metodológicas para construção e fortalecimento das competências que as avaliações da equipe sinalizam como prioritárias. $\mathrm{Na}$ elaboração das sequências didáticas sempre incluímos seminários, palestras com especialistas da comunidade, exposições e apresentações culturais realizadas pelos próprios estudantes. Nas aulas leitura, interpretação, produção e participação oral também são atividades sempre presentes em nossas propostas. Todas as estratégias visam o desenvolvimento de competências cognitivas, mas também a formação social e pessoal necessárias ao desenvolvimento da humanização e do convívio social saudável e produtivo. Ao final das propostas aplicamos uma avaliação interdisciplinar integralmente baseada na temática da unidade. (ESCOLA A apud BAHIA, 2021g, on-line).

Muitas sequências didáticas foram também disponibilizadas pela SEC por meio de materiais pedagógicos, no intuito de apoiar a prática pedagógica dos (as) professores (as), como os Cadernos de Apoio à Aprendizagem, nos quais contêm sequências didáticas por disciplina e ano. Averiguamos que a maioria das unidades escolares afirmou que está utilizando parcialmente, pois o associa a outros materiais, a fim de contemplar o planejamento feito pelos (as) professores (as) e realidade das turmas.

Além desses cadernos, a SEC também criou plataformas virtuais, como as Salas Virtuais no Google Classroom, Chatclass (Robôs de Aprendizagem) e Salas Centrais no WhatsApp, locais para gestão das atividades escolares não presenciais, para acesso e compartilhamento de materiais de apoio para as Trilhas de 
aprendizagem contidas nos cadernos de aprendizagem e exercícios de fixação. Percebemos que o acesso a esses ambientes pelas unidades escolares e, consequentemente, pelos (as) professores (as) foi bastante baixo, como podemos comprovar no Gráfico 1, a seguir:

Gráfico 1 - Acesso aos ambientes disponibilizados pela SEC

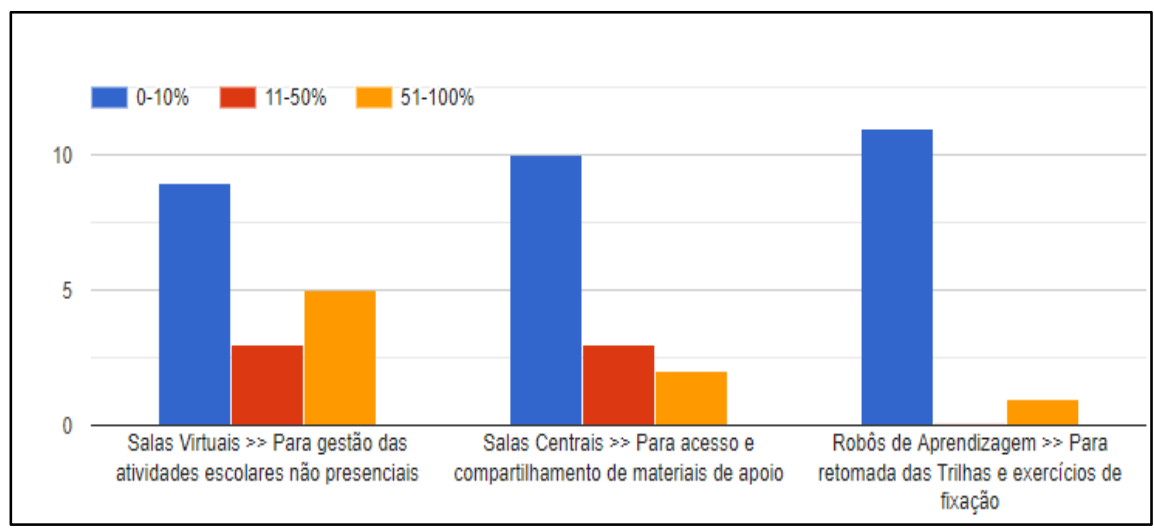

Fonte: Elaborado pelas autoras, 2021.

Vale a reflexão sobre os possíveis motivos que levaram as equipes escolares a não incorporarem esses suportes tecnológicos nas suas práticas pedagógicas, visto que a maioria dos (as) professores e alunos (as) usa celular (as), e essas plataformas foram programadas para acessar principalmente por esse aparelho. Assim, podemos questionar: os (as) professores (as) participaram de alguma formação para manusearem tais plataformas e as inserir em seu planejamento das aulas remotas? Pois, a formação do (a) professor (a) é um processo que incorpora as dimensões inicial e continuada.

Nesse contexto de inserção tecnológica buscamos também saber se as unidades escolares da EJA dispõem de suportes tecnológicos, como as salas de multiuso, locais onde ficam disponibilizados computadores com acesso à internet e impressora para os (as) alunos (as) e professores (as) que não dispõem desses suportes em sua residência. Apuramos que a maioria $(71,4 \%)$ das unidades escolares não possui essas salas.

Com essa informação, questionamos como as unidades escolares não oferecem uma simples estrutura, como sala de multiuso 
para seus (as) alunos (as) e professores (as) poderem ter a mínima possibilidade de acesso aos materiais disponíveis no formato digital, que corroboram com a qualidade do ensino remoto? Precisamos, como afirma Arruda (2020), "garantir equidade nas políticas de substituição da educação presencial pela educação mediada por tecnologias digitais [...]" (ARRUDA, 2020, p. 286), visto que o

Brasil não possui iniciativas no campo de tornar as tecnologias digitais como saberes necessários para uma formação transversal de alunos e alunas, diferente do que foi detectado na maioria dos países pertencentes à OCDE. (ARRUDA, 2020, p. 272).

De acordo com essa realidade, entendemos que o Ensino Remoto está se efetivando na maioria das unidades escolares da EJA, por meio de envio e recebimentos de atividades impressas, e o diálogo entre professores (as) e alunos (as) estão ocorrendo via Plantões Pedagógicos, ou seja, momentos em que o (a) professor (a) fica disponível para sanar possíveis dúvidas dos (as) alunos (as) em relação às atividades propostas nos roteiros de estudos impressos que foram disponibilizados.

Constatamos que esses Plantões acontecem na maioria das escolas (85\%) e em mais de $50 \%$ delas são realizados via celular, por meio de grupos de WhatsApp, que foram construídos por anos/séries ou por componentes curriculares para atendimento dos (as) alunos (as). Menos de $40 \%$ das escolas efetivam o Plantão no formato presencial, devido à necessidade do deslocamento dos (as) professores (as) e alunos (as) até a escola, mas as que realizam construíram um sistema de rodízio com hora marcada para não ter aglomeração.

A EJA, enquanto modalidade, possui diretrizes próprias, e entendemos que para atuar nessas turmas os (as) professores (as) precisam de uma formação e conhecimento de sua organização e funcionamento. O Plano 21 solicita que as escolas elenquem a quantidade de professores (as) que possuem: atualização (até 40 horas); extensão e/ou aperfeiçoamento (mínimo 180 horas); especialização (mínimo 360 horas); mestrado e/ou doutorado, ou se 
não possuem formação em EJA. Por intermédio das respostas fornecidas pela gestão das unidades escolares constatamos que a maioria das escolas não preencheu esse campo. Fato esse que impossibilita apresentarmos o perfil da formação desses profissionais.

O Plano 21 também reserva espaço para saber a quantidade de professores (as) que conhecem a Política Estadual de EJA da Bahia. Verificamos que somente $15 \%$ das unidades escolares destacaram que seus (suas) professores (as) a conhecem. Sabemos que o conhecimento dos documentos norteadores propostos por essa política é imprescindível para atuar na EJA, logo, as unidades escolares precisam promover momentos para o estudo desses documentos.

De acordo com a Política Estadual de EJA da Bahia (2009) o currículo da EJA deve ser "organizado de forma a possibilitar práticas dialógicas e emancipatórias" (BAHIA, 2009, p. 11). Então, precisa-se investir na formação dos (as) professores (as) que atuam na EJA para que eles/elas possam colocar realmente em prática esse currículo.

Verificamos que a maioria das unidades escolares (85,7\%) destacou que utilizam no planejamento pedagógico os OCEs da EJA, que estão organizados em:

[...] etapa do Ensino Fundamental - Anos Iniciais Eixos I, II, III - contemplam 2 (duas) áreas de conhecimento e seus componentes curriculares: Linguagens: Língua Portuguesa; Artes e Atividades Laborais e Matemática; Estudos da Natureza, da Sociedade: Geografia, História e Ciências [...];

Etapa do Ensino Fundamental - Anos Finais, Eixos IV e V - contemplam 4 (quatro) áreas do conhecimento e seus componentes curriculares: Linguagem: Língua Portuguesa, Língua Inglesa e Artes e Atividades Laborais; Matemática: Matemática; Ciências Humanas: Geografia e História; Ciências da Natureza: Ciências [...];

Etapa do Ensino Médio estão estruturados em 2 (dois) Eixos Temáticos, em que cada um possui 2 (duas) áreas do Conhecimento e seus componentes curriculares, sendo: Eixo VI - Linguagem: Língua Portuguesa, Língua Inglesa e Artes e Atividades 
Laborais; Ciências Humanas e Sociais Aplicadas: Geografia, História, Sociologia e Filosofia; o Eixo VII - Matemática: Matemática e Artes e Atividades Laborais; Ciências da Natureza: Química, Física, Biologia [...]. (BAHIA, 2021e, p. 5-6).

Por fim, no que tange à avaliação, percebemos que $80 \%$ das unidades escolares acompanham o percurso formativo da EJA. A maioria (81\%) utiliza as legendas e conceitos da EJA, contudo, quando se questiona: a unidade escolar utiliza notas e as transforma em conceito? Notamos que não há uma unanimidade em relação à utilização de notas e/ou conceitos na EJA, visto que 61,9\%, informaram que sim; $23,8 \%$ destacaram que não; e $14,3 \%$ não responderam. Porém, percebemos nos relatos registrados no Plano 21 que o processo de avaliação da aprendizagem ocorre com caráter investigativo, processual, contínuo, cumulativo e emancipatório, como preconiza a Portaria n. ${ }^{\circ} 6.562$ (BAHIA, 2016a), a Instrução Normativa n. ${ }^{\circ} 002$ (BAHIA, 2016b) e a Portaria n. ${ }^{\circ} 786$ (BAHIA, 2021f), que foi criada para dar conta das especificidades do continuum 2020/2021, na qual ressalta que é "obrigatória a realização de, no mínimo, 2 (duas) atividades avaliativas por unidade letiva, com um somatório de 10 pontos ou contemplando os conceitos de aproveitamento satisfatório das aprendizagens" (BAHIA, 2021f, ARTIGO 5०).

Tendo em vista a realidade registrada e analisada no Plano 21, nos documentos e plataformas de monitoramento da educação da Rede Estadual de Ensino da Bahia, no que tange à EJA, pudemos compreender como as escolas do Litoral Sul da Bahia se organizam para executar o Ensino Remoto. Ademais, as mesmas estão aprendendo a readaptar suas práticas pedagógicas e curriculares para "dar conta" do ano Continuum 2020/2021, em meio aos desafios que já existiam antes da pandemia e que foram intensificados devido à suspensão das aulas em 2020. Entretanto, precisam ser superados, principalmente, os relacionados à disponibilidade de suportes tecnológicos, que possibilitam a mediação da aprendizagem no formato não presencial. 


\section{BREVES CONSIDERAÇÕES}

Por meio das análises apresentadas no referido artigo verificamos que a EJA é ofertada no continuum 2020/2021 em 21 municípios dos 26 que fazem parte do Território de Identidade Litoral Sul (NTE 05). Portanto, precisamos refletir como são atendidos (as) os (as) Jovens e Adultos (as) dos municípios que a Rede Estadual de Ensino não oferta a EJA. Visto que devemos garantir o acesso e permanência dos (as) estudantes que não puderam concluir os estudos no Ensino Regular.

Nesse contexto, no que tange ao fluxo escolar, percebemos que no ano de 2019 a matrícula na EJA estava maior do que em 2020 e até 16 de abril de 2021 para o ano continuum 2020/2021, porém, já existia em 2019 uma alta taxa de abandono. Por isso, as unidades escolares mantêm o desafio de combater a evasão e o abandono que são tão presentes na EJA. Por consequência, precisam realizar ações de busca ativa de estudantes e estratégias que promovam a motivação e entusiasmo dos (as) alunos (as) a se manterem estudando e se qualificando para o trabalho, que é uma das temáticas incorporadas no currículo da EJA em todas as áreas para o desenvolvimento de competências e habilidades que favoreçam a (o) aluno (a) à inserção e permanência no mercado de trabalho. E ao mesmo tempo, que possa desafiá-lo (a) a refletir criticamente sobre sua realidade social.

Constatamos que as formas de organização curricular dessa modalidade durante o ano continuum 2020/2021 mantiveram o mesmo formato ofertado nos anos anteriores, oferecendo 35 vagas de matrículas para Tempos Formativos I e II, Tempo de Aprender I e Tempo Juvenil I e II. E 40 vagas para as turmas do Tempos Formativos III e Tempo de Aprender II. Segue a estrutura curricular disponibilizada nos OCEs da EJA para Ensino Fundamental (Anos Iniciais e Finais) e Ensino Médio. Com o desafio de realizar no Ensino Remoto práticas pedagógicas dialógicas e emancipatórias, com reflexões voltadas para temas pertinentes à realidade sociocultural, às questões éticas, à promoção da saúde, à preservação ambiental e à sexualidade, entre outros temas de princípios democráticos que contribuem para a formação holística do cidadão. 
Para tanto, destaca-se a necessidade de formação continuada dos (as) profissionais que atuam nas turmas da EJA. Visto que, ficou claro que muitos (as) estão lecionando nessa modalidade, mas desconhecem seus pressupostos teórico-metodológicos, o perfil do seu público, os documentos que a regulamenta no nível estadual e, em especial, a sua organização curricular e avaliativa.

Desse modo, para concretizar o Ensino Remoto na EJA, as escolas do NTE 05 utilizam em sua prática pedagógica recursos tecnológicos digitais e analógicos, que são planejados para momentos presenciais e não presenciais de acordo com a realidade da escola, dos (as) professores (as) e alunos (as). Por exemplo, a utilização de roteiros de estudos construídos pela SEC e disponibilizados em sites e plataformas digitais, bem como a possibilidade de imprimi-los, para assim poder atender ao público que não dispõe de suportes tecnológicos como computador e celular. Entretanto, um grande desafio é oportunizar esse acesso com qualidade para os (as) professores (as) e alunos (as), pois muitas escolas não possuem salas multiuso e os recursos destinados para impressão não são suficientes para atenderem a todos (as).

Em virtude dos dados coletados sobre a realidade da EJA nas escolas estaduais do Território de Identidade Litoral Sul (NTE 05), nesse ano continuum 2020/2021 em curso, depreendemos que, devese levar em conta as necessidades e especificidades das pessoas envolvidas nessa modalidade e de sua condição no desenvolvimento social, cultural, político e econômico, para dessa forma favorecer uma aprendizagem significativa com 0 fito de estimular 0 desenvolvimento pleno da cidadania e qualificação para o trabalho, prezando para o respeito ao direito de acesso aos conhecimentos socialmente produzidos, na busca da inclusão tecnológica e da equidade da educação ofertada.

\section{REFERÊNCIAS}

ALVES, Lynn. Educação Remota: entre a ilusão e a realidade. Revista Interfaces Científicas, Aracaju, v. 8, n. 3, p. 348-365, 2020. 
ARRUDA, E. P. Educação remota emergencial: elementos para políticas públicas na educação brasileira em tempos de Covid-19.

Em Rede: Revista de Educação a Distância. v. 7, n. 1, p. 257-275, 2020. Disponível em: https://www.aunirede.org.b r/revista/inde x.p hp/ emrede/article/view/621. Acesso em: 10 jul. 2020.

BAHIA (Estado). Decreto n. ${ }^{\circ} 19.586$ de 27 de março de 2020. Ratifica declaração de Situação de Emergência em todo o território baiano, para fins de prevenção e enfrentamento à COVID-19, e regulamenta, no Estado da Bahia, as medidas temporárias para enfrentamento da emergência de saúde pública de importância internacional decorrente do coronavírus. Diário Oficial do Estado da Bahia, 28 mar. 2020. Disponível em: http://www.legislabahia.ba. gov .br/documentos/decreto-no-19586-de-27-de-marco-de-2020. Acesso em: 10 mar. 2021.

BAHIA (Estado). Educação de Jovens e Adultos. 2021c. Disponível em: http://escolas. educacao.ba.gov.br/educacaojoveseadultos. Acesso em: 15 mar. 2021.

BAHIA (Estado). Indicadores Territoriais. Território de Identidade Litoral Sul. Superintendência de Estudos Econômicos e Sociais da Bahia. 2019. Disponível em: https://www.sei.ba.

gov.br/images/informacoes_por/territorio/indicadores/pdf/litoralsul. pdf. Acesso em: 10 mar. 2021.

BAHIA (Estado). Instrução Normativa n. ${ }^{\circ} 002 / 2016$. Orienta as unidades escolares da rede estadual de ensino da Bahia, na aplicação dos procedimentos de avaliação. 2016b. Disponível em: http://jornadapedagogica.educacao.ba.gov.br/wpcontent/uploads/2021/03/Instrucao-Normativa-002.2016Orientacao-as-Unidades-Escolares-1.pdf. Acesso em: 10 abr. 2021.

\section{BAHIA (Estado). Organizadores Curriculares Essenciais (OCE).} 2021e. Disponível em:

http://www.educacao.ba.gov.br/midias/documentos/organizadorescurriculares-essenciais. Acesso em: 15 mar. 2021.

BAHIA (Estado). Plano 21. Plataforma SAGA. 2021g. Disponível em: https://www. 
educacaobahia.com.br/escola/escola.php?modulo=principal/painel \&acao=A. Acesso em: 20 abr. 2021.

BAHIA (Estado). Política de EJA da Rede Estadual. Secretaria da Educação do Estado da Bahia. 2009. Disponível em: http://jornadapedagogica.educacao.ba.gov.br/ wpcontent/uploads/2020/01/Politica-da-EJA-2009.pdf . Acesso em: 10 mar. 2021.

BAHIA (Estado). Portaria n. ${ }^{\circ}$ 6.562/2016. Dispõe sobre a sistemática de Avaliação do Ensino e da Aprendizagem nas Unidades Escolares da Rede Estadual de Ensino, em todas as etapas da Educação Básica e suas modalidades. 2016a. Disponível em: http://jornadape dagogica.educacao.ba.gov.br/wpcontent/uploads/2021/03/PORTARIA-DE-AVALIACAO_-1.pdf. Acesso em: 10 abr. 2021.

BAHIA (Estado). Portaria N. ${ }^{\circ}$ 711/2021. Estabelece normas, procedimentos e cronograma para a renovação de matrícula escolar, de transferência de estudantes entre escolas da Rede Pública Estadual de Ensino e de matrícula escolar de estudantes oriundos das Redes Municipais de Ensino. 2021b. Disponível em: http://www.educacao.ba. gov.br/midias/documentos/portarian\%C2\%BA-7112021. Acesso em: 15 mar. 2021.

BAHIA (Estado). Portaria n. ${ }^{\circ}$ 786/2021. Dispõe sobre a sistemática de Avaliação da Aprendizagem e do Registro de Frequência dos (das) estudantes nas Unidades Escolares da Rede Estadual de Ensino.2021f. Disponível em: http://diarios.egba.ba.gov. br/html/DO09/fotos/executivo.pdf. Acesso em: 20 abr. 2021.

BAHIA (Estado). Proposta Pedagógica do Tempo Juvenil Ensino Fundamental para estudantes de 15 a 17 anos. Superintendência de Desenvolvimento da Educação Básica Diretoria de Educação e suas Modalidades Coordenação de Educação de Jovens e Adultos. 2013. Disponível em: http://www. educacao.ba.gov.br/midias/documentos/tempo-juvenil. Acesso em: 10 mar. 2021. 
BAHIA (Estado). Rendimento Escolar. Portal BI. Sistema de relatórios da Bahia, 2021a. Disponível em:

http://portalbi.educacao.ba.gov.br/relatorio/carregar/36. Acesso em: 15 mar. 2021.

BAHIA (Estado). Sistema de Gestão Escolar (SGE) Bahia. 2021d. Disponível em: http://sge.educacao.ba.gov.br/. Acesso em: 10 mar. 2021.

BAHIA (Estado). Territórios de Identidade. 2021h. Disponível em:http://www.seplan.ba.gov.br/modules/conteudo/conteudo.php? conteudo=17. Acesso em: 10 mar. 2021.

BAHIA. CONSED (org.). Gestores da SEC destacam ações realizadas em 2020 e perspectivas para 2021. 2021i. Disponível em: http://www.consed.org.br/central-de-conteudos/gestores-dasec-destacam-acoes-realizadas-em-2020-e-perspectivas-para-2021. Acesso em: 20 abr. 2021.

BRASIL. Lei $\mathbf{n} .^{\circ}$ 9.394, de 20 de dezembro de 1996. Diretrizes e Bases da Educação. Nacional (LDB). 1996. Disponível em: http://www.planalto.gov.br/ccivil_03/leis//9394.htm. Acesso em: 20 abr. 2021.

BRASIL. Parecer CNE/CEB n. ${ }^{\circ}$ 6/2010, de 9 de junho de 2010. Reexame do Parecer CNE/CEB n 23/2008, que institui Diretrizes Operacionais para a Educação de Jovens e Adultos - EJA, nos aspectos relativos à duração dos cursos e idade mínima para ingresso nos cursos de EJA; idade mínima e certificação nos exames de EJA; e Educação de Jovens e Adultos desenvolvida por meio da Educação a Distância. 2010b. Disponível em:

http://portal.mec.gov.br/ index.php?option=com_docman\&view $=$ download\&alias $=5366$ pceb006-10\&category_slug=maio-2010-pdf\&ltemid=30192. Acesso em: 20 abr. 2021.

BRASIL. Resolução n. ${ }^{\circ}$ 3, de 15 de junho de 2010. Institui Diretrizes Operacionais para a Educação de Jovens e Adultos nos aspectos relativos à duração dos cursos e idade mínima para ingresso nos cursos de EJA; idade mínima e certificação nos exames 
de EJA; e Educação de Jovens e Adultos desenvolvida por meio da Educação a Distância. 2010a. Disponível em:

http://portal.mec.gov.br/in dex.php?option= com_docman\& view $=$ download\&alias $=13448$-diretrizes-curiculares-nacionais-2013pdf\&lt emid=30192. Acesso em: 20 abr. 2021.

FONSECA, J. J. S. Metodologia da Pesquisa Científica. Fortaleza: UEC, 2002.

FREIRE, Paulo. Pedagogia da autonomia: saberes necessários à prática educativa. São Paulo: Paz e Terra, 1996.

HADDAD, Sérgio; DI PIERRO, Maria Clara. Aprendizagem de jovens e adultos: avaliação da década da educação para todos. São Paulo em perspectiva, v. 14, n. 1, p. 29-40, 2000.

KOSIK, K. Dialética do concreto. São Paulo: Paz e Terra, 2002.

MARCONI, Marina de Andrade; LAKATOS, Eva Maria. Fundamentos de metodologia científica. 5. ed., São Paulo: Atlas, ISBN 85-2243397-6, 2003.

MINAYO, M. C. S. (Org.). Pesquisa social: teoria, método e criatividade. 17. ed. Petrópolis: Vozes, 2000.

MOREIRA, José António; SCHLEMMER, Eliane. Por um novo conceito e paradigma de educação digital. Revista UFG, v.20, 63438. ISSN: 2179-2925. 2020.

\section{NÚCLEO TERRITÓRIAL DE EDUCAÇÃO LITORAL SUL. Relatório} interno da Educação do NTE 05. 2021.

OLIVEIRA, Maria Olívia de Matos. Políticas públicas e educação de jovens e adultos. Rev. Brasileira de Educação de Jovens e Adultos, v. 6, 2016. Disponível em:

https://www.revistas.uneb.br/index.php/educajovenseadultos. Acesso em: 27 maio 2018.

SANTOS, Arlete Ramos; LIMA, Lisângela Silva; NERY, Siomara Castro. Formação continuada dos professores da educação de jovens e adultos-campo em Itabuna-Bahia. Revista Amazônida. v. 4, n. 2. EISSN: 2527-0141, 2019. DOI: https://doi.org/10.29280/rappge.v4i2.4415. Disponível em: 
https://periodicos.ufam.edu.br/index.php/amazonida/ article/view/441

5\#: :text=Centrado\%20na\%20quest\%C3\%A3o\%20\%E2\%80\%9CA\%2 OForma\%C3\%A7\%C3\%A3o,fundamentado\%20no\%20Materialismo\% 20Hist\%C3\%B3rico\%20Dial\%C3\%A9tico. Acesso em: 20 abr. 2019.

SAVIANI, Demerval. Escola e Democracia. 43. ed. Campinas, SP: Editora Autores Associados. p. 32-35, 2018.

Submetido em: Junho/ 2021.

Aceito em: Setembro/ 2021. 